that methionine might benefit patients suffering from burns, at the stage where the appetite is too poor to allow of ingestion of adequate protein. An amount of $5 \mathrm{gm}$. per diem has been tolerated ${ }^{9}$.

Our thanks are due to the Medical Research Council for grants in aid of this research and to the Ministry of Supply for synthetic methionine and other amino-acids which made the work possible; to J. Jenkins for technical assistance and to colleagues in the Department for advice. The work has been carried out under the ægis of the Burns Sub-Committee of the War Wounds Committee, Medical Research Council.

Department of Biochemistry,

University, Oxford. Dec. 23.

${ }^{1}$ Cuthhertson, D. C., Biochem. J., 24, 1244 (1930); for review, see Lancet, i, 433 (1942).

${ }^{2}$ Clark, E. J., Peters, R. A., and Rossiter, R. J., Report to Med. Res. Council (1943) and Quart. $J$. Exp. Physiol. (in the press).

3 Taylor, F. H. L., Levenson, S. M., Davidson, C. S., Browder, N. C., and J,und, C. C., Ann. Surg., 118, 215 (1943).

- Croft, P. B., and Peters, R. A., Report to Med. Res. Council (1944) and Lancet (in the press).

5 Wilson, W. C., unpublished reports to War Office and Med. Res. Council (1942). Wells, D. B., et al., New Engl. J. Med., 226, 629 (1942). Erb, I. H., Morgan, E. M., and Farrer, A. W., Ann. Surg., 117, 234 (1943).

${ }^{6}$ Cameron, G. R., Milton, M., and Allen, J. W., Lancet, ii, 179 (1943). Barnes, J. M., and Rossiter, R. J., Lancet, ii, 218 (1943). Hartmanes, F. W., and Romence, H. L., Ann. Surg., 118, 402 (1943)

' Colebrook et al., Med. Res. Council Special Report, No. 249 (1944). Cameron, G. R., et al., J. Path. Bact., in the press.

${ }^{8}$ For reviews, see Best, C. H., and Lucas, C. C., "Vitamins and Hormones", vol. I (New York, 1943); MeHenry, E. M., and Patterson, J. M., "Physiol Reviews" (1943); a also Channon,

Peters, R. A., Thompson, R. H. S., King, A. J., Williams, D. I., Nicol, C. S., Greenwood, M., and Martin, W. S., Nature, 153, $773(1944)$ and Quart. $J$. Med., in the press.

\section{Colour Phenomena in Ultra-Violet Vision}

The note by $\mathrm{N}$. I. Pinegin ${ }^{1}$ suggests a more detailed discussion of the relation between the threshold intensities for scotopic and photopic vision in the ultra-violet. The threshold ratio $T_{p} / T_{s}$ is a measure of the intensity range, often misleadingly called 'photochromatic interval', in which the visual impression is free from the specific colour sensation. This intensity range is a marked function of the position of the illuminated area on the retina, the threshold ratio increasing with increasing angle from the fovea. Since Pinegin's note does not contain any data for this angle, it is difficult to draw definite conclusions from his results.

It seems, therefore, a suitable opportunity to record the results of measurements of the threshold ratio at $365 \mathrm{~m} u$ for four normal observers and one observer with an aphakic eye. These measurements were made in 1938 in connexion with investigations on the photosensitivity of visual purple and scotopic vision in the ultra-violet ${ }^{2}$. The threshold ratio was determined using the same observers and apparatus as described in the previous paper for the measurement of the absolute scotopic sensitivity at $365 \mathrm{~m} \mu$. The procedure adopted was as follows :

After 5 minutes dark adaptation, monochromatic light flashes of about 1 second duration were viewed with the parafoveal region of the retina $10^{\circ}$ temporal or nasal for right or left eye of the observer respectively. (The illuminated retinal area was a circular patch subtending an angle of $2 \cdot 6^{\circ}$ in the normal eyes and $4 \cdot 4^{\circ}$ in the aphakic eye.) The intensity of the flashes was twice slowly decreased and increased, and the relative intensities noted which corresponded to the disappearance and reappearance of the 'colourless' (scotopic) visual sensation and the colour (photopic) sensation. This procedure occupied 8-11 minutes. The mean values for the threshold ratio arrived at from the observations and shown in the table correspond, therefore, to a mean dark adaptation of $9-10.5$ minutes. Little variation of $T_{p} / T_{s}$ with dark adaptation was found after the first 5 minutes.

\begin{tabular}{|c|c|c|c|}
\hline Observer & Age & Eye & $\log _{10}\left(T_{p} / T_{8}\right)$ \\
\hline G.C. & 27 & $\mathbf{R}$ & 1.8 \\
\hline C.F.G. & 34 & $\mathbf{R}$ & $2 \cdot 3$ \\
\hline R.J.L. & 42 & $\mathbf{L}$ & $2 \cdot 3$ \\
\hline E.E.S. & 27 & $\mathbf{L}$ & $2 \cdot 1$ \\
\hline A.G.G. & 26 & $\mathrm{~L}$ & $2 \cdot 7$ \\
\hline
\end{tabular}

Assuming that Pinegin's results for the absolute photopic threshold were obtained in a comparable retinal region, we get in conjunction with the results from our earlier paper for the absolute scotopic sensitivity a value $\log _{10} T_{p} / T_{s}=2.6$ at $365 \mathrm{~m} \mu$, in fair agreement with the above table. A value of $\log _{10} T p / T_{s}=2 \cdot 7$ at $546 \mathrm{mu}$ derived from the same sources could be compared with the measurements of Wentworth ${ }^{3}$ which gave values of $\log _{10} \cdot T_{p} / T_{s}=1.8$ and $2 \cdot 2$ at 522 and $582 \mathrm{~m} \mu$ respectively and at $a_{0}$ retinal position of $10^{\circ}$ from the fovea.

The most remarkable result of our measurements is the appearance of a elearly defined second chromatic threshold in the aphakic eye. An increase of the light intensity in the region of violet sensation above the first threshold led to a point where there is a sharp transition from violet to a distinctively blue sensation. Furthermore, this transition point could be reproduced quite accurately irrespective of whether it was approached from above or below. The value of two logarithmic units derived from the table above represents, therefore, a definite quantitative measure for the intensity interval between the blue-violet point and the violet-colourless point. It seems likely that this effect is a consequence of the extremely high sensitivity of the aphakic eye in the ultra-violet, where it is found to be of the same order as in the visible part of the spectrum. The sensitivity of normal eyes was found to be about 10,000 times smaller at $365 \mathrm{~m} \mu$ than at $546 \mathrm{~m} \mu$. As this difference is due to the presence in normal eyes of an absorbing substance in front of the perceptive organs of the retina rather than to a difference of the process of vision in the two spectral regions, it is to be assumed that the complex colour vision is also present in normal eyes but not clearly observable at usually available light intensities. An indication of its presence in normal eyes may be found in the widely diverging descriptions of the subjective colour of ultra-violet light, ranging from distinctive blue to distinctive violet, and in the frequent observation of Goodeve (private communication) that a strong mercury arc viewed through a deep violet filter which passes only the $405 \mathrm{~m} \mu$ line, looked quite blue.

E. E. SCHNEIDER.

Department of Physics,

King's College, Newcastle-upon-Tyne, University of Durham.

${ }^{1}$ Pinegin, N. I., Nature, 154, 770 (1944).

2 Goodeve, C. F., Lythgoe, R. J., and Schneider, E. E., Proc. Roy. Soc., B, 130, 380 (1942).

3 Wentworth, H. A., Psycholog. Mon., 40 (1930). See Duke Elder, "Textbook of Ophthalmology", 1, 898 and 910 .

4 Saidman and Dufestel, C.R. Acad. Sci., 182, 1173 (1926). Saidman, J., C.R. Acad. Sci., 196, 1537 (1933). de Groot, W., Nature, 134 494 (1934). Gaydon, A. G., Proc. Phys. Soc., 50, 714 (1938). 